\title{
Uma Abordagem Metodológica Experimental para Relacionar Emoções e Aprendizagem Utilizando Reconhecimento de Expressões Faciais
}

\section{An Experimental Methodological Approach to Relate Emotions and Learning Using Facial Expressions Recognition}

Carla Marina Paxiúba

Programa de Computação

Universidade Federal do Oeste do Pará

carla.paxiuba@ufopa.edu.br

\author{
Celson Pantoja Lima \\ Programa de Computação \\ Universidade Federal do Oeste do Pará \\ Celson.lima@ufopa.edu.br
}

\section{Resumo}

Atualmente é amplamente aceito que as emoções influenciam significativamente o processo de aprendizagem. Porém como reconhecer as emoções do aluno e como relacionar os vários tipos de emoções ao aprendizado, permanece uma questão em aberto. Este artigo apresenta um modelo de ensino que utiliza as emoções do aluno para apoiar o processo de ensino e de aprendizagem. As emoções dos alunos são obtidas automaticamente por meio de uma ferramenta de software para reconhecimento de expressões faciais. Os dados gerados pela ferramenta servem de embasamento para estabelecimento de correlações individuais e coletivas entre as emoções dos alunos e seu desempenho nas avaliações.

Palavras-Chave: Reconhecimento de Emoções; Modelo de Aprendizagem; Sinais Corporais.

\begin{abstract}
Nowadays is widely accepted that emotions significantly influence the learning process. But how to recognize the student's emotions and how to relate the various types of emotions to learning remains an open question. This article presents a teaching model that uses the student's emotions to support the teaching and learning process. Students' emotions are obtained automatically through a software tool for facial expressions recognition. The data generated by the tool serve as a basis for establishing individual and collective correlations between the students' emotions and their performance in the evaluations.
\end{abstract}

Keywords: Emotion Recognition; Learning Model; Body Signals.

Cite as: Paxiuba, C.M, Lima, C.P. (2020). An Experimental Methodological Approach Working Emotions and Learning Using Facial Expressions Recognition (Uma Abordagem Metodológica Experimental para Trabalhar Emoções e Aprendizagem Utilizando Reconhecimento de Expressões Faciais). Brazilian Journal of Computers in Education (Revista Brasileira de Informática na Educação - RBIE), 28, 92-114. DOI: 10.5753/RBIE.2020.28.0.92 


\section{Introdução}

A tradicional dicotomia entre razão e emoção existente na sociedade ocidental, herdada da visão dualista de Descartes sobre mente e corpo, contribuiu para que pouca atenção fosse dada ao papel da afetividade na aprendizagem e em outras atividades cognitivas no século passado. Porém, trabalhos de psicólogos e neurologistas têm destacado o importante papel da motivação e da afetividade em atividades cognitivas (Damasio, 1996).

De acordo com Piaget (1989), o papel acelerador ou perturbador da afetividade na aprendizagem é incontestável. Ele afirma que uma boa parte dos estudantes que são fracos em matemática falha devido a um bloqueio afetivo. Os trabalhos de Izard (1984) mostram que emoções negativas induzidas prejudicam o desempenho em tarefas cognitivas, e emoções positivas têm um efeito contrário. Mora (2013) diz que tudo o que promove a aquisição de conhecimento, como curiosidade, atenção, memória para tomada de decisão, requer a energia que conhecemos como emoção.

O campo da Inteligência Artificial que pesquisa sobre emoção em computadores é chamado de Computação Afetiva (“Affective Computing”). Picard (1997) define Computação Afetiva como "computação que está relacionada com que surge de, ou deliberadamente influencia emoções”. O campo é dividido em dois ramos maiores de pesquisa. O primeiro estuda mecanismos para reconhecer emoções humanas ou expressar emoções por máquinas na interação homem-computador. O segundo ramo investiga a simulação de emoções em máquinas (síntese de emoções) a fim de descobrir mais sobre as emoções humanas e construir robôs que pareçam mais reais. Reconhecendo o papel significativo das emoções e a influência destas no processo de aprendizagem e o crescimento da área de computação afetiva, este trabalho apresenta uma abordagem metodológica para investigar as relações entre emoções e aprendizagem com o apoio de uma solução tecnológica, desenvolvida pelos autores, para reconhecimento de emoções a partir das expressões faciais dos alunos. O objetivo do modelo é avaliar as possíveis correlações existentes entre os elementos do modelo proposto, sendo eles emoções, expressões faciais, disciplinas, conteúdos, perfil do estudante e aprendizagem.

Este artigo está organizado da seguinte maneira: Na seção 2 é apresentado o conceito de emoções e suas correlações com o processo de aprendizagem. A seção 3 faz uma revisão dos trabalhos correlatos. Na seção 4 o modelo de ensino baseado no reconhecimento das emoções dos alunos a partir de suas expressões faciais proposto neste trabalho, é detalhado. A seção 5 traz a ferramenta Cara de Aprender - CADAP, desenvolvida no escopo deste trabalho, que atua como suporte ao modelo de ensino apresentado. A seção 6 traz os resultados preliminares obtidos até o momento com a aplicação do modelo.

\section{Emoções}

A definição de emoção pode parecer simples, uma vez que esse termo é utilizado no cotidiano com frequência. Contudo, na psicologia, a definição de emoção não é tão simples. Na literatura atual as emoções não são mais compreendidas como uma reação única, mas como um processo que envolve múltiplas variáveis. Nesse sentido, emoção poderia ser definida como uma condição complexa e momentânea que surge em experiências de caráter afetivo, provocando alterações em várias áreas do funcionamento psicológico e fisiológico, preparando o indivíduo para a ação (Atkinson et al, 2002; Davis \& Lang, 2003; Gazzaniga \& Heatherton, 2005; Levenson, 1999). Quando se trata de definir os componentes da emoção, a maioria dos modelos teóricos atuais incluem reação muscular interna, comportamento expresso, impressão afetiva subjetiva e cognições. A literatura comumente considera que o estudo dos aspectos subjetivos e cognitivos 
das emoções foi negligenciado entre as décadas de 1930 a 1960 devido à, então, popularidade do behaviorismo e sua crítica aos processos “mentalistas” (Goodwin, 2005; Ledoux, 1996; Mandler, 2003; Niedenthal et al., 2006; Plutchik, 2002; Schultz \& Schultz, 2009; Strongman, 2003).

O senso comum até hoje dita que as expressões emocionais têm origem em algum evento interno, ou seja, nós sentimos alguma coisa e então expressamos uma emoção. A ordem desses fatores, porém, pode não ser exatamente essa. Uma das primeiras referências nesse sentido foi James (1890), que afirmava que primeiramente os humanos percebem o estímulo, havendo uma reação do organismo, e a percepção desse movimento das vísceras seria, então, o próprio sentimento. Segundo os exemplos do próprio autor, nós não correríamos porque sentimos medo, mas sim sentiríamos medo porque começamos a correr. Apesar de pouco intuitiva, essa proposta mostrou-se popular na primeira metade do século XX, especialmente, graças ao surgimento do behaviorismo, respaldando o conceito de que os comportamentos não teriam origem interna, mas externa e observável (James, 1890).

As teorias psicoevolucionistas propõem que os estados emocionais existem hoje como reflexo da evolução das espécies, ou seja, como respostas adaptativas a situações que ocorrem no meio. Desde Darwin (1872), entende-se que, embora certas formas de manifestação das emoções possam ser aprendidas, existem expressões, especialmente as faciais, que são inatas, tanto para os seres humanos quanto para chimpanzés e outros primatas. Isso poderia ser verificado, por exemplo, em crianças que nascem cegas e, ainda assim, expressam sorrisos de felicidade ou choro na tristeza, da mesma maneira que pessoas sem problemas de visão. Outro fator levado em conta foi a similaridade na expressão de estados emocionais entre culturas diferentes, ou seja, o fato de que, em todas as culturas, alegria é expressa com sorriso, raiva com franzimento das sobrancelhas e tensão dos lábios, e assim por diante. Esses dados levaram à consideração da existência de emoções básicas ou primárias características da espécie humana. Nesse sentido, as emoções humanas teriam evoluído de um conjunto finito de estados emocionais, sendo que cada um deles possuía sua funcionalidade adaptativa e expressão típica (Ekman, 2003; Gazzaniga \& Heatherton, 2005; Lundqvist \& Öhman, 2005; Markham \& Wang, 1996; Plutchik, 2002). Por exemplo, segundo os autores dessas teorias, ao longo da evolução, indivíduos que demonstraram uma reação clara e distinta frente a um perigo, dessa maneira comunicando a presença da ameaça ao resto do grupo e permitindo o preparo ou fuga, apresentaram vantagem evolutiva e foram selecionados, resultando na existência da emoção chamada de medo.

Apesar de existiram diferentes formas de expressar emoções, a maioria das pesquisas foca na expressão facial. Ekman (2003) e Plutchik (2002) consideram que essa situação possa ser explicada pelo fato de justamente a face ser a região corporal humana com maiores recursos para expressão, uma que seus principais músculos estão concentrados na região oral, sendo também responsáveis pela mastigação, o que resulta na possibilidade de movimentação em diversas direções. Músculos que também estão envolvidos na expressão facial são os músculos das sobrancelhas, da testa, das pálpebras e do pescoço, embora estes possuam menor liberdade de direções. Na literatura é comum se encontrar a nomenclatura "emoções básicas" para distinguir diversas classes desse fenômeno. Porém, assim como não existe um consenso quanto ao modelo teórico que explica o funcionamento emocional, também não existe uma definição em relação a quantas e quais são as emoções básicas. Contudo, a maioria dos autores costuma citar as seguintes ou alguma variação delas: alegria, medo, surpresa, tristeza, nojo, desprezo e raiva. Suas expressões faciais típicas estão representadas na Figura 1. 


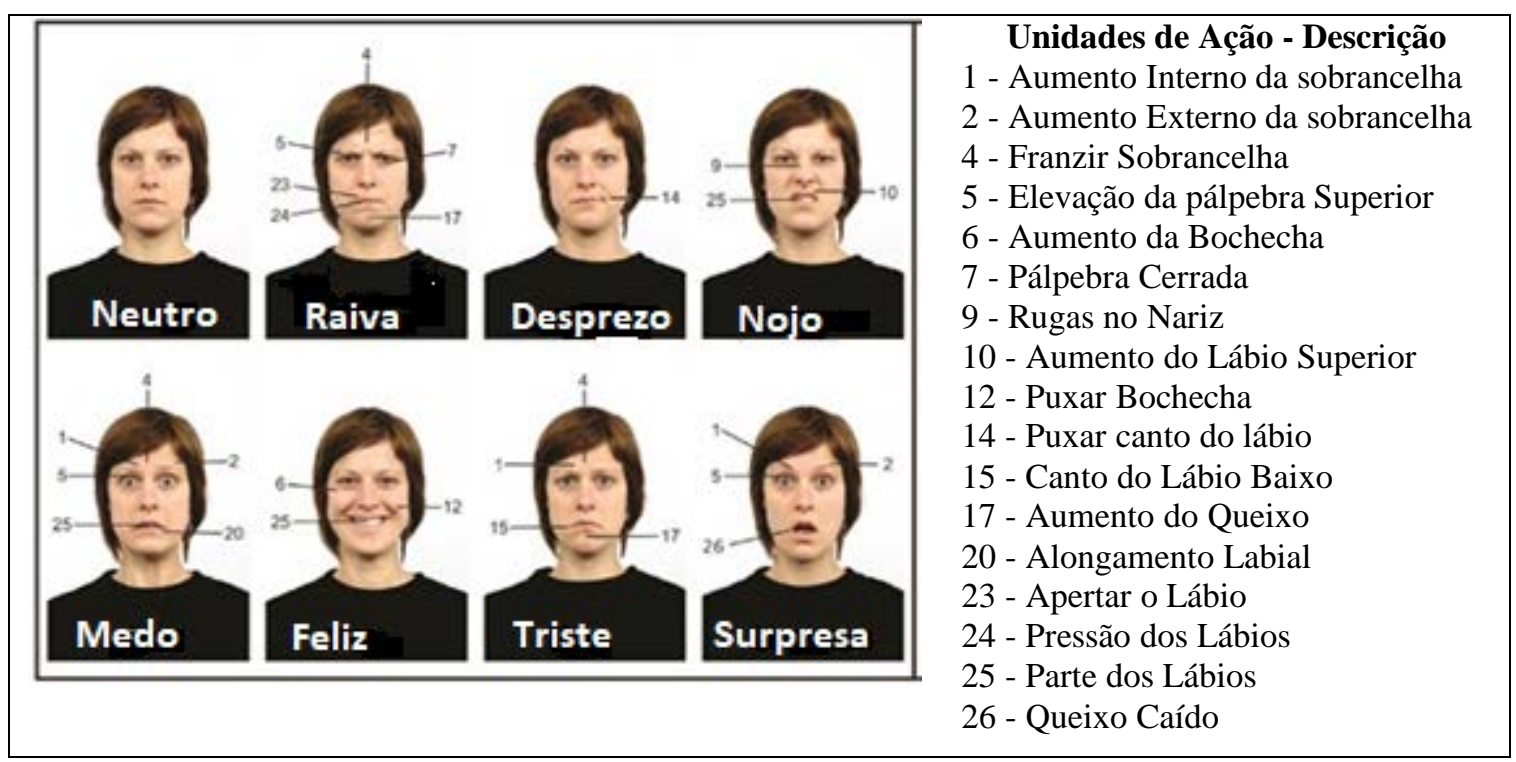

Figura 1. Expressões faciais típicas (Adaptado de Ekman, 2003)

\subsection{Emoções e Aprendizagem}

Vários psicólogos e pedagogos, tais como Piaget (1989), Vygotsky (1994), Goleman (1995) e Mora (2013) têm destacado o papel importante da motivação e da afetividade na aprendizagem. Para Piaget (1989), sem afetividade o sujeito não teria interesse para desvendar problemas ou fazer descobertas. A inexistência de perguntas, por falta de interesse ou motivação, pode representar um obstáculo para o desenvolvimento da inteligência. De acordo com Piaget (1989), é incontestável que as emoções aceleram ou perturbam a aprendizagem, e que não existe aprendizagem sem afetividade e vice-versa. Goleman (1995) aponta a maneira pela qual os distúrbios emocionais afetam a vida mental. Ele chama a atenção para a ideia bem conhecida de que alunos deprimidos, mal-humorados e ansiosos encontram maior dificuldade em aprender. Os trabalhos de Izard (1984) mostram que emoções negativas induzidas no estudante costumam prejudicar o seu desempenho em tarefas cognitivas e emoções positivas possuem um efeito contrário. Coles (1998) chama atenção para estudos realizados que mostraram que induzir um humor triste em uma criança aumenta o tempo que ela leva para realizar uma tarefa e ainda aumenta o número de erros. A mesma pesquisa mostrou que resultados contrários foram alcançados quando foi induzida alegria. Coles (1998) também destaca estudos que mostraram que crianças identificadas como em risco na escola completaram exercícios de matemática mais precisamente quando foram induzidas emoções positivas.

Mora (2013) afirma que através do estudo das atividades de diferentes áreas do cérebro foi verificado que somente pode ser verdadeiramente aprendido aquilo que chama a atenção e gera emoção. Aquilo que é diferente e sobressai a monotonia. Para Mora, os ingredientes que influem para inovar e melhorar o ensino e aprendizagem são a emoção, a empatia, a curiosidade e os mecanismos de atenção. Um outro fator fundamental à aprendizagem é a motivação. Enquanto motivados, os alunos buscam encontrar resposta aos seus problemas e satisfazer suas necessidades. Para Vygotsky (1962), a motivação é a razão da ação. É a motivação que impulsiona as necessidades, interesses, desejos e atitudes particulares dos sujeitos.

O pensamento tem sua origem na esfera da consciência, uma esfera que inclui nossas inclinações e necessidades, nossos interesses e impulsos, e nossos afetos e emoções. A tendência afetiva está por trás do pensamento. Somente aqui encontramos a resposta para o "porquê" final na análise do pensamento (Vygotsky, 1962). No que se refere ao papel da afetividade na aprendizagem, Vygotsky (1962) propõe a unidade entre os processos intelectuais, evolutivos e 
afetivos. Segundo ele, o afeto não pode ser dissociado da cognição: Quando abordamos o problema da inter-relação entre pensamento e linguagem e outros aspectos da mente, a primeira questão que surge é a do intelecto e do afeto. Sua separação como sujeitos de estudo é uma grande fraqueza da psicologia tradicional, pois faz com que o processo de pensamento apareça como um fluxo autônomo de "pensamentos pensando-se" segregados da plenitude da vida, das necessidades e interesses pessoais, das inclinações e impulsos da vida do ser pensante” (Vygotsky, 1962).

Em uma de suas últimas publicações, Vygotsky (1994) apresenta um novo conceito introduzindo afetividade na aprendizagem: perezhivanie. O desenvolvimento de uma criança depende da maneira que a criança experimenta uma situação no ambiente, isto é, "como uma criança se torna consciente de, interpreta, e emocionalmente se relaciona com um certo evento" (Vygotsky, 1994). Neste trabalho ele apontou o importante papel da emoção no desenvolvimento infantil.

Coles (1998) considera que como um professor pode contribuir para o desenvolvimento das habilidades cognitivas do aluno, ele também pode assistir no desenvolvimento emocional da criança através de instrução e suporte. Como Coles (1998) aponta:

"O medo do fracasso pode ser mudado para sentimentos de autoconfiança; a motivação pode mudar de baixa para alta; a insegurança intelectual pode tornar-se confiança na inteligência de alguém. Essas transformações podem ocorrer através do "suporte" de um professor e da orientação na formação de novos estados emocionais que um aprendiz pode alcançar e sustentar por si mesmo.”

Além das questões afetivas e emocionais onde este trabalho se centra cabe destacar que também avançam pesquisas baseadas em estudos da neurologia e, principalmente, da genética, que buscam correlacionar estes fatores com a aprendizagem. Estas pesquisam contam com o suporte de técnicas de inteligência artificial cada vez mais avançadas. Este estudo propõe um modelo de ensino baseado no reconhecimento das emoções dos alunos com o objetivo de estabelecer correlações com aprendizagem.

\section{Trabalhos Correlatos}

Alguns modelos e ferramentas para o reconhecimento de emoções dos alunos a partir de sinais corporais com o objetivo de correlacionar as emoções com aprendizagem são encontrados na literatura. Trabalhando com reconhecimento através de sinais fisiológicos, Picard (1997) alcançou bons resultados com o reconhecimento de oito emoções (neutro, raiva, ódio, tristeza, amor platônico, amor romântico, alegria e veneração) com uma taxa de sucesso de $81 \%$. Os sinais usados foram: batimento cardíaco, eletromiograma, condutividade da pele e respiração. Geralmente, estes mecanismos de reconhecimento, como, por exemplo, reconhecimento por expressões faciais, incluem um hardware que detecta os sinais fisiológicos e um software que é responsável por decodificar a informação enviada pelo equipamento. Wehrle \& Kaiser (2000) registraram em vídeo as expressões faciais de usuário jogando e usaram um software para reconhecimento de expressões faciais com objetivo de automaticamente analisar o comportamento facial gravado. Pode-se reconhecer as emoções do aluno apenas analisando as suas expressões faciais ou sua voz, mas, geralmente, os sensores fisiológicos não são usados como mecanismos isolados para inferir as emoções do aluno. Visto que eles fornecem apenas algumas evidências sobre o "arousal” (excitamento), valência e outras informações sobre emoções, eles são usados como mecanismos auxiliares para inferir emoções mais precisamente, ou em conjunto. Alguns exemplos de indícios detectados por sensores fisiológicos são (Conati \& Zhou, 2002; 
Picard, 1997): a) A condutividade da pele é um bom indicador do nível de arousal; e b) Os batimentos cardíacos aumentam na presença de emoções com valência positiva.

Um dos primeiros trabalhos que propôs a integração de modelo afetivo de aluno em um ambiente educacional foi o desenvolvido por Elliot (1997). Ele apresenta o uso do framework Affective Reasoner em um ambiente pedagógico para modelar emoções do estudante. O framework Affective Reasoner (AR) (Elliott \& Brzezinski, 1998; Elliott, 1997) utiliza agentes inteligentes, que são entidades autônomas capazes de observar um ambiente através de sensores e atuar sobre este, e especificamente neste ambiente, são responsáveis por responder emocionalmente. Os agentes possuem pseudo-personalidades representando os objetivos individuais do agente em relação aos eventos que podem acontecer, os princípios em relação às ações intencionais do agente, as preferências em relação aos objetos, humor, assim como um conjunto de 440 canais para expressão de emoções. Por exemplo, um agente pode avaliar o sucesso do usuário em uma atividade como sendo desejável para ele (um amigo), produzindo uma emoção de alegria por alguém e levando a uma expressão de orgulho por seu bom trabalho. Para se comunicar com o usuário, os agentes usam vários canais multimídia. Os agentes podem ter expressões faciais que são desenhadas em tempo real, produzindo em torno de 3000 formas. As formas são geradas na máquina cliente, quando elas são exibidas. Para falar com o usuário, os agentes usam um sintetizador de voz, o que lhes permite construir dinamicamente as sentenças que serão faladas e tocar músicas para aumentar a expressão de emoções. Os agentes também possuem um software de reconhecimento de voz para responder em tempo real ao usuário, embora não haja um entendimento de ponto de vista da linguagem natural (o agente não entende nada além de emoções).

Conati \& Zhou (2002) propõem um modelo probabilístico para inferir emoções do estudante em um jogo educacional. O modelo é implementado com Dynamic Decision Networks (DDNs) que são uma extensão das redes bayesianas. O modelo considera seis emoções (alegria, aflição, orgulho, vergonha, admiração e reprovação), e contém variáveis que representam os objetivos do estudante, variáveis de decisão que representam as ações do agente (que indicam pontos que o agente tem que se decidir e como intervir) e uma classe de nós-Goals_Satisfied que representa a desejabilidade de um evento. Os objetivos são inferidos pela personalidade do estudante e pelo modo como os estudantes jogam (por exemplo, os estudantes que têm o objetivo have_fun (divertimento) tendem a se mover mais rapidamente no jogo).

A fim de determinar os possíveis objetivos do estudante, foi apresentado um questionário para 23 estudantes que estavam sob observação durante o jogo. O modelo faz também a distinção entre emoções de si próprio (do aluno) e emoções para com o agente (como as emoções admiração e reprovação). As emoções do estudante em relação a um parceiro no jogo não foram implementadas. $\mathrm{O}$ uso da DDN e das redes bayesianas provaram ser ferramentas poderosas para modelar emoções, pois permite representar explicitamente as dependências probabilísticas entre as causas, os efeitos e os estados emocionais, o que possibilita determinar as emoções do estudante com mais exatidão nas situações que o usuário experimenta uma grande variedade das emoções (Conati \& Zhou 2002).

De Vicente e Pain (2002) modelaram o estado motivacional do aluno baseado em fatores tais como controle, desafio, independência, fantasia, confiança, interesse sensorial, interesse cognitivo, esforço e satisfação, que são capturados através do comportamento observável do aluno. Para determinar que ações são indicações de fatores afetivos, eles observaram interações gravadas no MOODS, um ambiente computacional de aprendizagem. Bercht e Vicari (2001) definiram um modelo afetivo dinâmico baseado em uma abordagem Belief-Desire-Intentiom BDI (Georgeff et al., 1999) que considera os fatores autoconfiança, independência e esforço para detectar o estado motivacional do aluno. 
D’Mello et al. (2010) propuseram um sistema de tutoria inteligente (Auto Tutor) que tem como objetivo desenvolver um ambiente de aprendizagem ágil que seja sensível ao estado afetivo do aluno, presumindo que isso promoverá o aprendizado. Este sistema classifica as emoções com base nas expressões faciais, movimentos corporais e tons de conversação. Em 2012, D’Mello et al., utilizando este mesmo ambiente, investigaram as transições entre estados afetivos medidos pela ferramenta (tédio, engajamento confusão, frustração, alegria e surpresa) durante o aprendizado, enquanto os estudantes universitários eram orientados em informática pelo Auto Tutor. Vídeos dos rostos dos participantes e os históricos de interação foram gravados e depois reproduzidos para os participantes para julgarem seus próprios estados afetivos. Foi desenvolvida uma métrica para medir a probabilidade relativa de transição de um estado afetivo no tempo ti para um estado afetivo subsequente no tempo $(\underline{\mathbf{t} \mathbf{i}+\mathbf{1})}$. As intenções originais deste estudo eram usar várias medidas discretas (diálogos, expressões faciais, postura corporal) para diagnosticar 0 efeito do aluno, e depois para modificar as estratégias pedagógicas do Auto Tutor para reagir de forma sistemática e rápida aos estados afetivos e cognitivos do aluno. No entanto, este estudo identificou que os alunos que vivenciam estados afetivos negativos, como o tédio e a frustração, têm maior probabilidade de mergulhar nesses estados do que de se transformar em estados positivos de engajamento, deleite ou mesmo confusão. Isso sugere que uma política reativa rápida de simplesmente tentar promover transições desses estados negativos para emoções correlacionadas positivamente com a aprendizagem pode não ser suficiente. Em vez disso, ou além disso, é melhor incluir medidas preditivas para determinar o início desses estados afetivos negativos, juntamente com estratégias pedagógicas proativas para contornar a incidência de emoções negativas.

A abordagem proposta neste trabalho reúne algumas características dos trabalhos mencionados como reconhecimento de emoções a partir de sinais fisiológicos, expressões faciais, com o objetivo de correlacionar as emoções dos alunos com aprendizagem. Porém difere das abordagens citadas ao buscar associar as emoções dos alunos, aos conteúdos apresentados, as metodologias de ensino utilizadas, aos estilos de aprendizagem dos estudantes, assim trazendo novos elementos e novas possibilidades de correlações.

\section{Modelo de Ensino Baseado no Reconhecimento das Emoções dos Alunos a partir de suas Expressões Faciais}

Psicólogos e pedagogos têm apontado como as emoções podem interferir positivamente (quando o aluno está motivado e sentindo emoções positivas) e negativamente (quando o aluno está malhumorado e deprimido por exemplo) na aprendizagem de um aluno. Neste contexto, este trabalho apresenta um modelo que utiliza as emoções dos alunos para melhorar o processo de ensino e de aprendizagem, e, para isto, dentre outras coisas, utiliza o suporte tecnológico de uma ferramenta para captura de expressões faciais dos estudantes durante as aulas, para que posteriormente possam ser feitos correlações entre as expressões faciais dos estudantes, as emoções, e a aprendizagem dos conteúdos. Esta ferramenta deve capturar as expressões dos alunos e as classificar em sete tipos distintos de emoções: alegria, tristeza, surpresa, medo, nojo, desprezo e raiva. A captura será feita durante toda a exibição da videoaula, e ao final será emitido um relatório por discente, que apresentará as emoções que predominaram. Quando o docente cadastrar avaliações objetivas na ferramenta com objetivo de avaliação, a captura das emoções também ocorrerá na ocasião que o aluno estiver realizando a atividade avaliativa.

Todas estas informações serão armazenadas para que sejam analisadas e possam ser realizadas futuras correlações como por exemplo - o Aluno A que teve expressões de alegria durante 50 a $70 \%$ do tempo em que foi apresentado o conteúdo Alfa, obteve melhor desempenho 
na aprendizado do conteúdo, do que o aluno B que prevaleceu apenas 30\% expressando alegria durante a apresentação do mesmo conteúdo. Importante ressaltar que forma de avaliação de aprendizagem será definida pelo professor. Caso ele opte por uma prova objetiva, poderá realizar o cadastro da avaliação na ferramenta.

Sendo assim, a maior contribuição desta pesquisa é o estabelecimento de correlações entre as emoções dos alunos e seu processo de aprendizagem, através da utilização de técnicas computacionais como reconhecimento de expressões faciais e algoritmos de aprendizagem de máquina. Para que seja possível efetuar estas correlações, esta abordagem prevê um processo que possui um conjunto de etapas e elementos que serão detalhados a seguir.

\subsection{Elementos do Processo}

No processo de ensino e de aprendizagem baseado nas emoções definido neste trabalho, há um conjunto de elementos que devem estar presentes, detalhados na Tabela 1.

Tabela 1 - Elementos do Processo

\begin{tabular}{|l|l|}
\hline Elemento & Descrição \\
\hline Discente & $\begin{array}{l}\text { Terá suas expressões faciais capturadas durante a visualização de aulas e } \\
\text { avaliações para que sejam analisadas as emoções que ocorreram durante o } \\
\text { processo. }\end{array}$ \\
\hline Docente & Desenvolverá e/ou apresentará o conteúdo didático apresentado aos discentes \\
\hline $\begin{array}{l}\text { Conteúdo } \\
\text { Pedagógico }\end{array}$ & $\begin{array}{l}\text { Conteúdos que serão apresentados pelos docentes aos discentes durante o } \\
\text { processo }\end{array}$ \\
\hline $\begin{array}{l}\text { Objeto de } \\
\text { Aprendizagem }\end{array}$ & $\begin{array}{l}\text { Uma entidade, digital ou não digital, que pode ser usada e reutilizada ou } \\
\text { referenciada durante um processo de suporte tecnológico ao ensino e } \\
\text { aprendizagem }\end{array}$ \\
\hline Emoções & $\begin{array}{l}\text { Alterações de ânimo que serão monitoradas durante as aulas. Neste trabalho } \\
\text { serão monitoradas as emoções: alegria, tristeza, desprezo, nojo, surpresa, } \\
\text { medo e raiva. }\end{array}$ \\
\hline $\begin{array}{l}\text { Ferramenta de } \\
\text { Captura de } \\
\text { Expressões } \\
\text { Faciais }\end{array}$ & $\begin{array}{l}\text { Software de Captura e Análise de Expressões Faciais dos alunos que será } \\
\text { utilizado durante todo o processo. }\end{array}$ \\
\hline
\end{tabular}

\subsection{Etapas do Processo}

Um processo pode ser representado através do encadeamento de eventos e atividades, ligados através de conectores que demonstram a sequência em que eles são realizados. Além de eventos e atividades, outros elementos de controle de fluxo podem ser utilizados na modelagem para permitir a criação ou unificação de fluxos paralelos que ocorram no decorrer de um mesmo processo. Esta abordagem foi seguida para proposição do processo de ensino e de aprendizagem baseada nas emoções dos alunos proposto neste trabalho e apresentado na Figura 2. Este processo possui cinco etapas descritas a seguir e que serão detalhadas nas próximas seções.

- Modelagem do Perfil do Estudante.

- Modelagem dos conteúdos curriculares das disciplinas.

- Aplicação e Avaliação do conteúdo.

- Avaliação do conteúdo. 
- Análise dos Resultados.

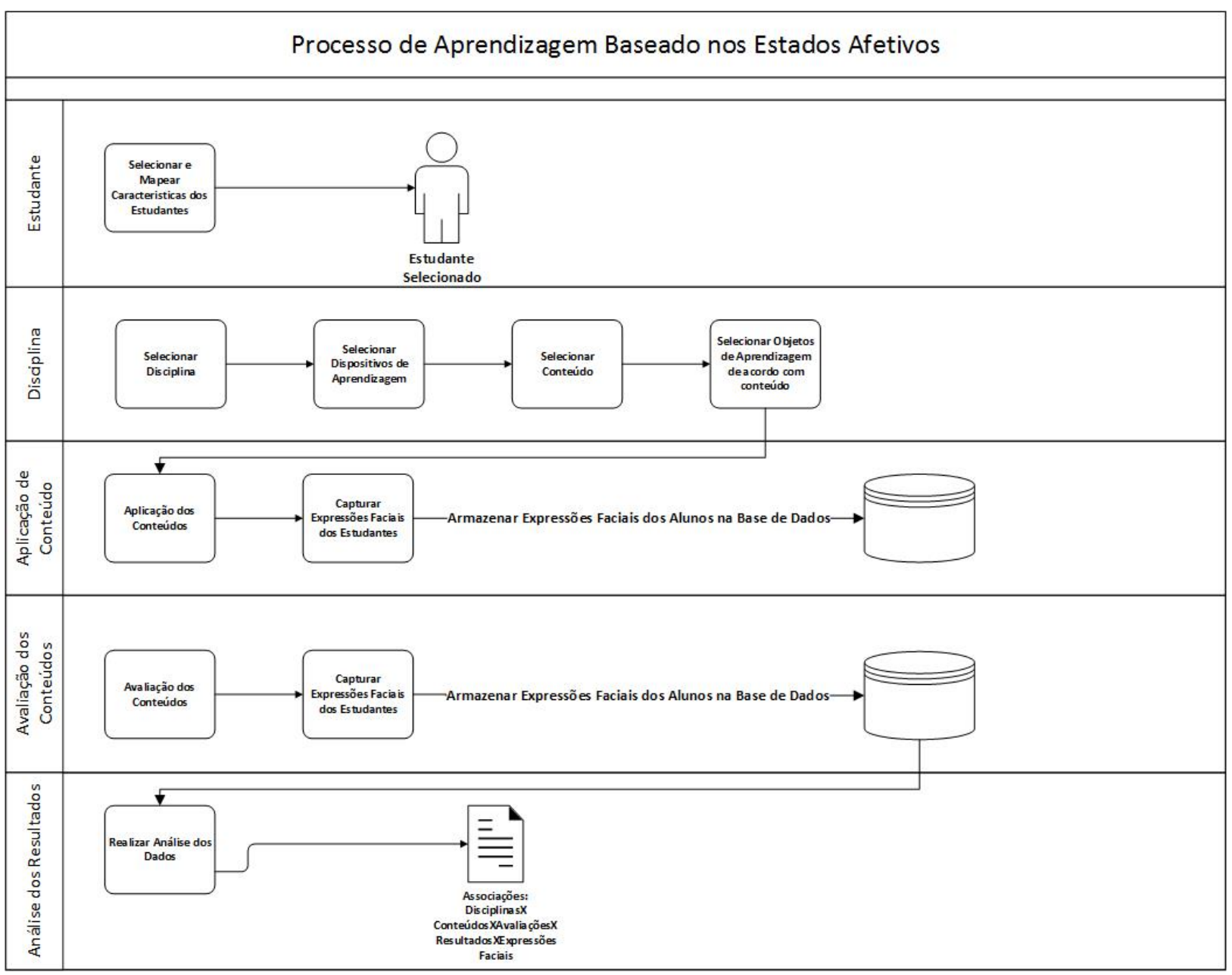

Figura 2. Modelo de Ensino Baseada na Emoção dos Alunos

\subsubsection{Etapa 1 - Modelagem do Perfil do Estudante}

Um perfil de estudante é composto por um conjunto de propriedades que caracterizam o estudante como: sua identificação pessoal, suas características pessoais e sociais, seu perfil de aprendizagem, seu conhecimento sobre determinados assuntos, entre outros. Algumas informações relativas ao perfil do estudante, como sua identificação pessoal, preferências pessoais e sociais, são raramente modificadas. Em contrapartida, informações que envolvem aspectos cognitivos como seu estilo de aprendizagem e seu conhecimento sobre um dado assunto, podem ser alterados. Além disso, as informações sobre os aspectos cognitivos estão diretamente relacionadas ao ambiente e ao escopo de aprendizagem, fazendo com que seja necessário a ocorrência de alterações dentro deste contexto. (Dolog et al., 2005; Lee et al., 2005).

Uma questão fundamental dentro da área de modelagem do estudante é determinar como construir modelos concisos que representem da melhor forma os aspectos cognitivos de um aluno em relação ao ambiente em que este se encontra. Um dos pontos é identificar qual estilo de aprendizagem está associado ao estudante para que seja possível traçar o perfil de aprendizagem dele. Um estilo de aprendizagem está relacionado às estratégias que um aluno tende a aplicar com frequência a uma dada situação de ensino. Estilos de aprendizado se referem às características individuais que um aluno tem de organizar, perceber, processar, lembrar e pensar para resolver um problema (Liu \& Ginther, 1999; Triantafillou et al., 2003). 
No escopo deste trabalho será adotado o modelo de Felder \& Silverman (1988) para classificar os estudantes em relação a seu perfil de aprendizagem. Os autores propuseram um modelo de estilos de aprendizagem considerando métodos de ensino que pudessem atender tais estilos, e este foi o motivo da adoção deste modelo neste trabalho, por possuir uma relação entre os estilos de aprendizagem e os respectivos métodos de ensino adotados para atender tais estilos.

Segundo Felder \& Silverman (1988), um aluno pode ser classificado por um conjunto de estilos de aprendizagem. Isto porque cada um dos estilos descritos observa uma dimensão diferente do comportamento do aluno durante a aprendizagem. Baseado no trabalho de Felder \& Silverman foi criado um instrumento chamado índice de Estilos de Aprendizagem que é utilizado para determinar as preferências em quatro dimensões (ativo/reflexivo, sensorial/intuitivo, visual/verbal e sequencial/global) do modelo de estilos de aprendizagem formulado por Felder \& Silverman (1988). Na utilização do Índice de Estilos de Aprendizagem, o usuário deverá estar atento para dois pontos importantes: 1 . Os resultados fornecem uma indicação das preferências individuais de aprendizagem e, provavelmente, uma indicação ainda melhor do perfil de preferências de um grupo de estudantes (por exemplo, uma turma), mas eles devem ser utilizados com cautela. 2. O perfil do estilo de aprendizagem de um estudante fornece uma indicação dos prováveis pontos fortes e possíveis tendências ou hábitos que poderiam estar conduzindo a dificuldades na vida acadêmica. O perfil não reflete a adequabilidade ou inadequabilidade do estudante para/ com uma determinada matéria, curso ou profissão. O primeiro passo ao utilizar a abordagem metodológica proposta neste trabalho é utilizar este formulário para classificar os alunos de acordo com seu estilo de aprendizagem baseado no instrumento.

Para a modelagem do perfil do aluno, além do seu estilo de aprendizagem, serão consideradas também as seguintes informações:

- Faixa Etária

- Sexo

- Grau de Escolaridade

- Média Escolar

O objetivo de realizar esta classificação na metodologia é possibilitar futuras análises que possam correlacionar o perfil do aluno, as emoções expressadas e o desempenho dos discentes nas avaliações dos conteúdos.

\subsubsection{Etapa 2 - Modelagem dos Conteúdos Curriculares.}

Esta proposta prevê que os conteúdos curriculares utilizados devam ser classificados quanto à abordagem de ensino utilizada: Baseada em Problemas, Baseada em Projetos, Sala de Aula Invertida, Palestra. É importante classificar corretamente os conteúdos em relação à abordagem, pois, é pretensão deste trabalho avaliar a abordagem mais adequada de acordo com o perfil de aprendizado, as emoções detectadas e os resultados das avaliações de cada discente mediante a apresentação dos conteúdos. Para a modelagem dos conteúdos serão armazenadas as seguintes informações:

- Conteúdo

- Tema

- Abordagem de Ensino

- Forma de Avaliação

- Questões de Avaliação, se o tipo de avaliação for objetivo. 


\subsubsection{Etapas 3 e 4 - Aplicação e Avaliação dos Conteúdos}

O núcleo da abordagem proposta neste trabalho é a utilização de uma ferramenta de captura e reconhecimento de expressões faciais durante as aulas. Esta ferramenta possibilita analisar as emoções dos alunos e correlacioná-las com fatores como perfil de aprendizagem do aluno, dispositivos de aprendizagem utilizado pelo professor e desempenho do aluno. Para que isto seja possível, durante as aulas os alunos serão filmados e a ferramenta irá capturar e analisar as expressões faciais dos alunos e, assim, construirá uma base de conhecimento dos alunos e de suas emoções. Ao final de cada aula, o aluno deverá preencher um instrumento, em que avaliará as emoções percebidas por ele durante as aulas. O objetivo deste instrumento é comparar as emoções percebidas pelos alunos, com as emoções detectadas pela ferramenta.

A avaliação do conteúdo será feita de acordo com o que o docente definir. Caso seja constituída de questões avaliativas objetivas, o docente pode cadastrar estas questões na ferramenta e o aluno ter suas emoções analisadas durante a execução da avaliação na ferramenta. Nesta opção os dados referentes a taxa de acertos dos alunos são coletados automaticamente. Caso a avaliação seja feita de outra forma - questões subjetivas, apresentação de trabalhos, desenvolvimento de projetos - o docente deve informar o resultado da avaliação na ferramenta, para que seja possível realizar análise dos resultados e estabelecer correlações entre as emoções dos alunos e sua aprendizagem.

\subsubsection{Etapa 5 - Análise dos Resultados}

A etapa de análise dos dados é a mais importante deste processo, pois nela é feita o estabelecimento de correlações entre os elementos do processo. Para isto esta etapa irá trabalhar com cruzamento de informações dos elementos. Este cruzamento irá começar analisando informações em dois níveis, posteriormente os níveis serão incrementados conforme a Tabela 2. As correlações de duas e três dimensões são geradas automaticamente pela ferramenta, através de relatórios e gráficos. A correlação de quatro dimensões exige análises mais detalhadas e ainda não está sendo gerada de forma automática, porém pode ser feita manualmente através da análise dos dados gerados pela ferramenta. Importante ressaltar que estas correlações irão variar de acordo com os estudantes, turmas, conteúdos e disciplinas, não sendo objetivo deste trabalho encontrar correlações universais e sim correlações para cada grupo analisado.

Tabela 2 - Correlações entre Emoções e Aprendizagem

\begin{tabular}{|l|l|l|}
\hline Duas Dimensões & Três Dimensões & Quatro Dimensões \\
\hline $\begin{array}{l}\text { Aplicação de Conteúdo X } \\
\text { Expressão Facial }\end{array}$ & $\begin{array}{l}\text { Perfil do Aluno X Expressão } \\
\text { Facial X Aplicação de } \\
\text { Conteúdo }\end{array}$ & $\begin{array}{l}\text { Perfil do Aluno X Expressão } \\
\text { Facial X Conteúdo X Resultado }\end{array}$ \\
\hline $\begin{array}{l}\text { Resultado da Avaliação X } \\
\text { Expressão Facial }\end{array}$ & $\begin{array}{l}\text { Perfil do Aluno X Expressão } \\
\text { Facial X Resultado da } \\
\text { Avaliação }\end{array}$ & $\begin{array}{l}\text { Disciplina X Conteúdo X } \\
\text { Resultado da Turma X Perfis na } \\
\text { Turma }\end{array}$ \\
\hline $\begin{array}{l}\text { Aplicação de Conteúdo X X } \\
\text { Resultado da Avaliação }\end{array}$ & $\begin{array}{l}\text { Perfil do Aluno X Aplicação } \\
\text { do Conteúdo X Resultado da } \\
\text { Avaliação }\end{array}$ & \\
\hline
\end{tabular}

Um exemplo de análise de correlações proposto neste modelo pode ser visualizado na Figura 3. As informações referentes as emoções são coletadas automaticamente pela ferramenta de software proposta neste trabalho. Porém as informações relacionadas a avaliação devem ser fornecidas pelo docente, que indica qual a forma de avaliação que irá adotar. Estas informações 
devem ser cadastradas pelo docente no momento que registrar a aula no software e posteriormente o docente deve informar o resultado da avaliação de aprendizagem dos alunos. Com estes dados a ferramenta irá gerar relatórios conforme Figura 3 realizando correlações entre a média das emoções dos alunos, com seus resultados na avaliação. No exemplo da Figura 3, a avaliação é baseada nas evidências de desenvolvimento de habilidades, conhecimento e competências pelo aluno. Com análises como esta acredita-se que o docente poderá avaliar as correlações entre os resultados da avaliação e as emoções dos alunos reconhecidas através das suas expressões faciais.

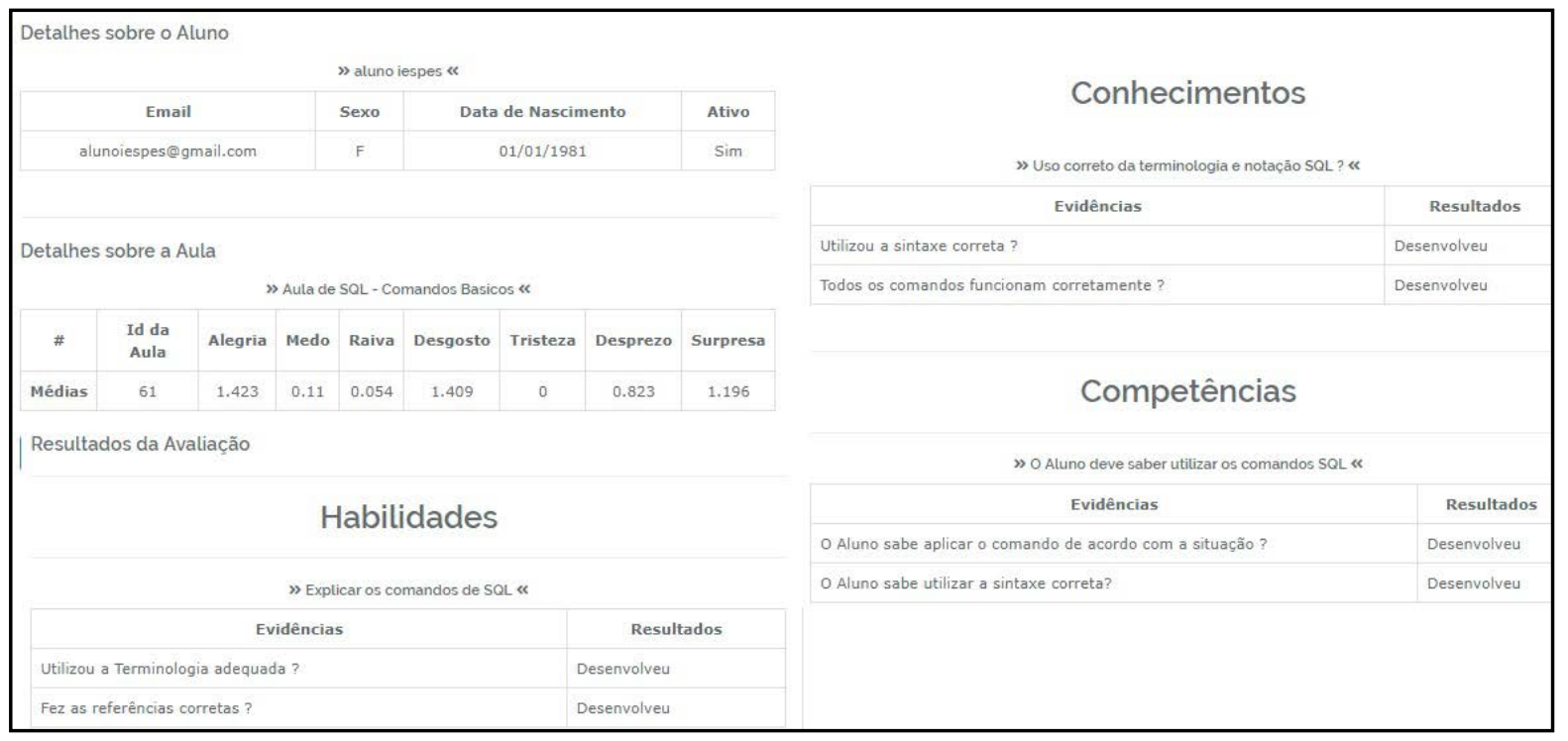

Figura 3: Média de Emoções e Desempenho de um Aluno

O modelo também prevê que as análises poderão considerar dimensões como o perfil de aprendizagem do aluno, a metodologia de ensino utilizada pelo professor na videoaula, e demais elementos do modelo. Importante destacar que a adequação dos conteúdos didáticos deve ser feita pelos docentes, A ferramenta apenas indica as reações emocionais que os alunos apresentam mediante o conteúdo. As análises previstas pelo modelo possibilitarão atuar em duas frentes detalhadas a seguir.

Diagnóstico: As análises dos resultados possibilitarão diagnósticos do que ocorreu no processo de ensino e de aprendizagem dos alunos, como:

- Percentual de alunos que permaneceram com emoções positivas/negativas;

- Conteúdos que despertaram maior índice de emoções positivas/negativas.

Correlações entre emoções e taxas de acerto nas avaliações poderão ser realizados a partir da análise dos dados coletados. Com estes diagnósticos, os docentes poderão realizar ajustes nas suas metodologias de ensino com objetivo de melhorar a aprendizagem dos discentes.

Predição de Informações: Além da realização de diagnósticos, acredita-se que a ferramenta pode evoluir para realizar predições, pois a partir dos dados coletados pode-se inferir informações com a aplicação de técnicas de inteligência artificial. Inferências como as citadas a seguir poderão ser realizadas:

- $\mathrm{O}$ aluno A tem $\mathrm{X} \%$ de chance de ter emoções positivas com este conteúdo, ao passo que o aluno B tem Y\% de chance;

- O conteúdo A tem X\% de chance de obter reações emocionais positivas da turma;

- Se o conteúdo for apresentado em uma determinada abordagem metodológica, tem maior chance de reações emocionais positivas da turma. 
A predição de informações permitirá aos docentes uma melhor tomada de decisões relacionadas a forma de apresentação, conteúdo e real conhecimento das percepções dos seus alunos. Além disso, conforme visto em D’Mello et al. (2010), os alunos que vivenciam estados afetivos negativos têm maior probabilidade de mergulhar nesses estados do que de se transformar em estados positivos. Isso sugere que uma política reativa rápida de simplesmente tentar promover transições desses estados negativos para emoções correlacionadas positivamente com a aprendizagem pode não ser suficiente. Em vez disso, ou além disso, é melhor incluir medidas preditivas para determinar o início desses estados afetivos negativos, juntamente com estratégias pedagógicas proativas para contornar a incidência de emoções negativas. Neste caso seria melhor prever as reações que os conteúdos despertarão nos alunos para possibilitar ao docente a tomada de decisões e melhor avaliação dos materiais didáticos.

\section{A Ferramenta de Software Cara de Aprender - CADAP}

A ferramenta Cara de Aprender - CADAP (disponível em www.cadap.net) foi desenvolvida em um contexto que visa estudar as relações entre as emoções do aluno, os dispositivos de aprendizagem, os conteúdos utilizados e a performance dos alunos. Este trabalho optou por trabalhar com reconhecimento de emoções a partir das expressões faciais pois a maioria das pesquisas foca na expressão facial. Ekman (2003) e Plutchik (2002) consideram que essa situação pode ser explicada pelo fato de justamente a face ser a região corporal humana com maiores recursos para expressão, uma vez que seus principais músculos estão concentrados na região oral, sendo também responsáveis pela mastigação, o que resulta na possibilidade de movimentação em diversas direções. Desta forma, foi implementada uma ferramenta de software denominada Cara de Aprender - CADAP que segue esta abordagem.

Nesta ferramenta, a captura das expressões faciais dos alunos é feita durante as aulas e avaliações (em caso de avaliações objetivas cadastradas na ferramenta), armazenando estes dados em uma base de dados e posteriormente realizando análises que permitam estabelecer correlações entre perfil de aprendizagem dos alunos, dispositivos de aprendizagem utilizados, emoções registradas e desempenho dos alunos nas avaliações.

A ferramenta CADAP permite que sejam cadastradas videoaulas, turmas, avaliações para os alunos, bem como a visualização de aulas, com a respectiva captura de expressões faciais e emissão dos resultados, por aula e por turma. Na atual versão do CADAP, a captura de expressões faciais dos alunos e correlações com as emoções é realizada no momento que o aluno visualiza videoaulas cadastradas na ferramenta. Este cenário atende o objetivo deste projeto de estudar as correlações de emoções com o processo de aprendizagem do aluno. Para o cenário tradicional de sala de aula, a ferramenta deverá ser adaptada e existe a necessidade de equipar a sala de aula com câmeras para captura das expressões faciais dos alunos.

Na Figura 4, no menu superior direito, é possível visualizar a imagem da face do aluno sendo capturada, enquanto este assiste aula na ferramenta. Ao finalizar a aula a ferramenta guarda as emoções que prevaleceram nos alunos durante a visualização do conteúdo. 


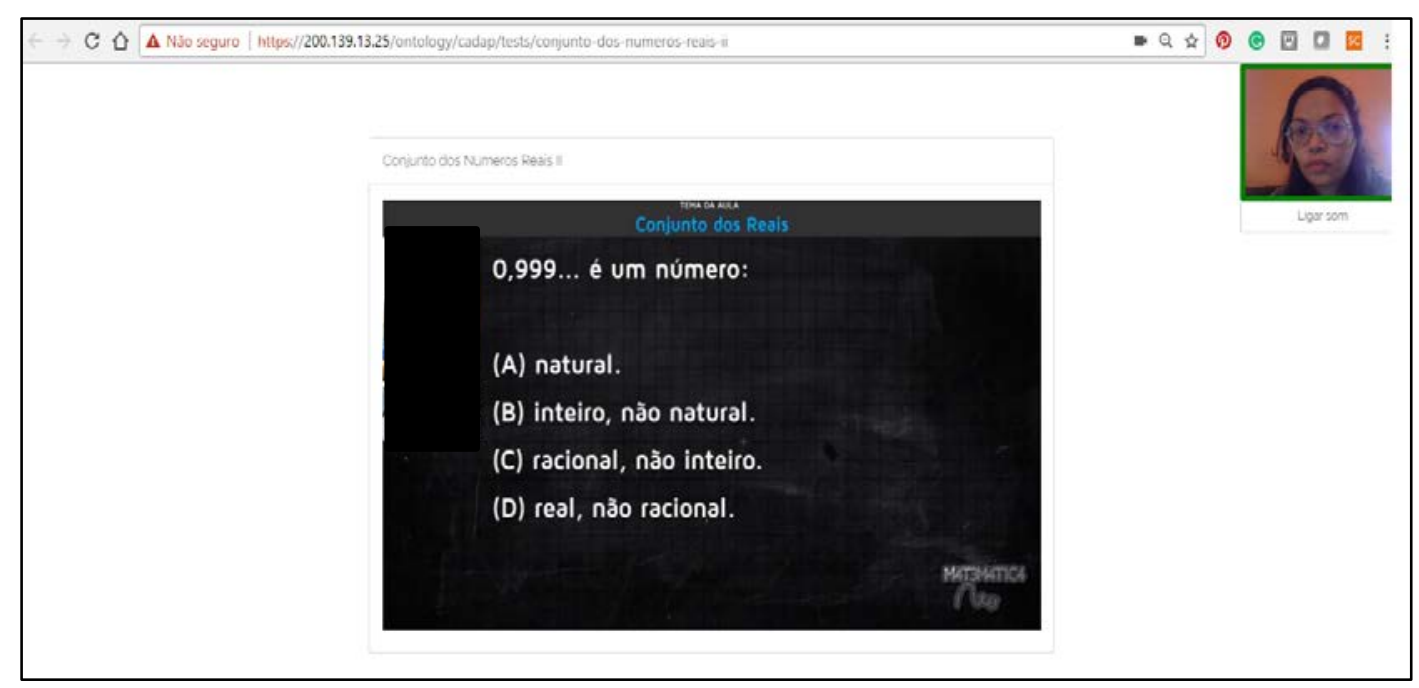

Figura 4. Tela de Visualização de Aulas e Captura de Expressões Faciais

A Figura 5 mostra um gráfico gerado após o aluno assistir uma videoaula no CADAP. Neste gráfico, é possível acompanhar a variação das sete emoções que a ferramenta analisa alegria, tristeza, surpresa, medo, raiva, nojo e desprezo. Com isso é possível verificar o momento da aula que houve variação significativa de emoções, quais emoções prevaleceram durante a aula, e posteriormente analisar se o desempenho do aluno está relacionado às emoções positivas e/ou negativas observadas no aluno durante a aula, dentre outras possíveis conclusões. As emoções variam em uma escala de 0 a 100 (zero a cem), onde zero indica que a emoção não está presente e cem indica que a emoção está no ápice. No gráfico exibido na Figura 5, o eixo y apresenta esta escala de variação (0 mínimo de emoção e 100 o máximo), e o eixo x apresenta o tempo do vídeo medido em segundos. No gráfico em questão a emoção que atingiu o ápice, em tempos distintos, foi a emoção de desprezo,

Para que o aluno possa visualizar as aulas na ferramenta os professores devem cadastrar para cada aula os vídeos, o tema, a abordagem utilizada e conteúdos referente as aulas, conforme pode ser visto na Figura 6. Caso queira o professor também pode cadastrar questões avaliativas que serão apresentadas durante a exibição do vídeo, de acordo com a configuração de tempo feita pelo docente.

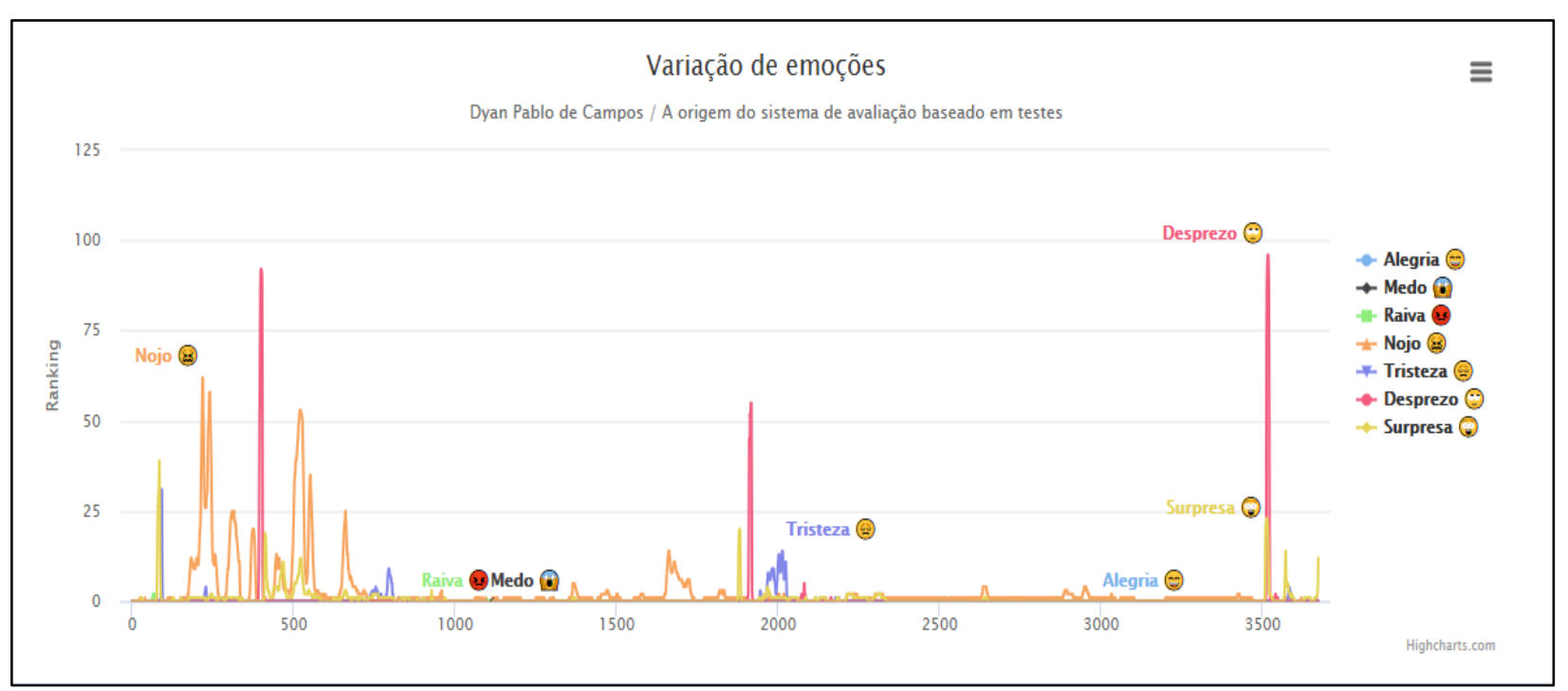

Figura 5. Gráfico de Variação de Emoções dos Alunos 


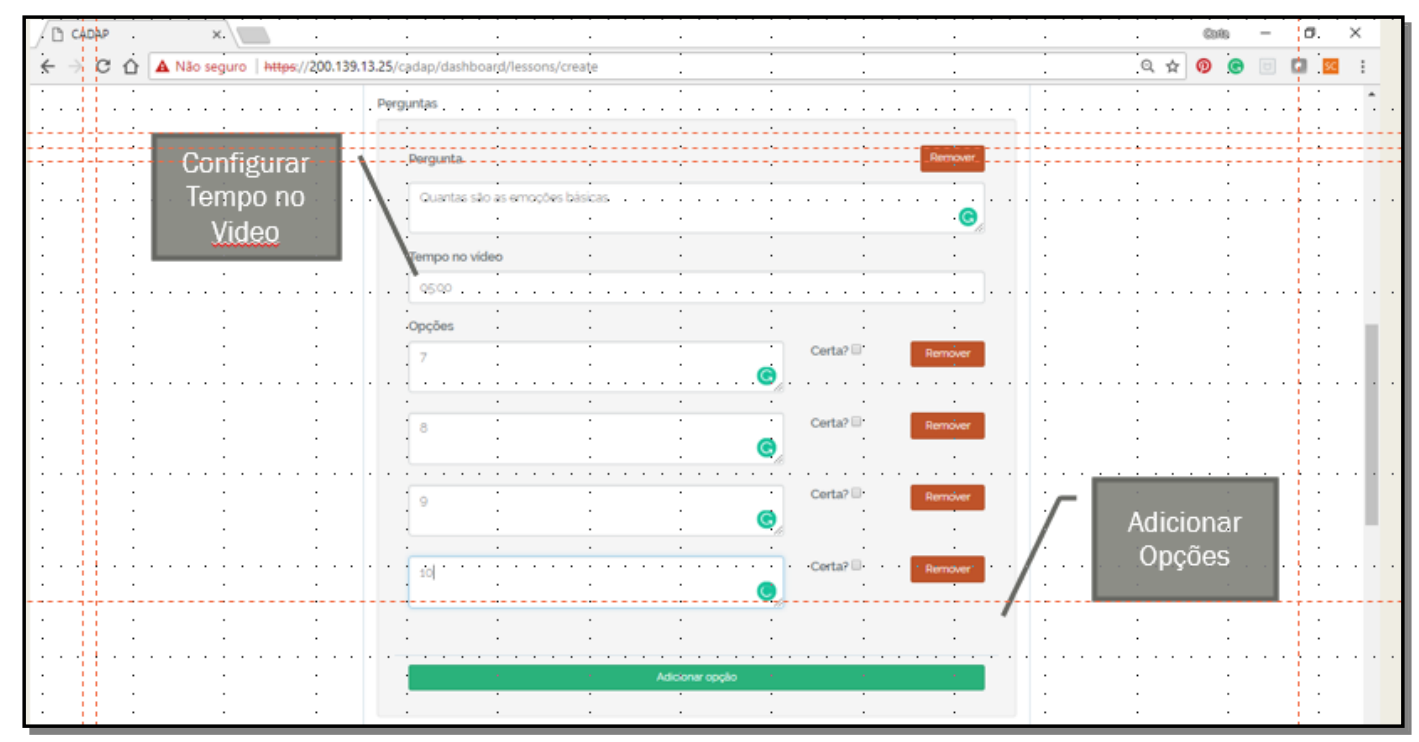

Figura 6. Cadastro de Aulas na Ferramenta

\subsubsection{Componente de análise de expressões faciais}

Affectiva (https://www.affectiva.com/) é uma empresa de tecnologia de medição de emoções que cresceu a partir do Media Lab do MIT(Massachusetts Institute of Technology). A Affectiva desenvolveu um software para reconhecer emoções humanas com base em pistas faciais ou respostas fisiológicas. A tecnologia desenvolvida pelo Affectiva (Mcduff et al., 2013) identifica primeiro um rosto humano em tempo real ou em uma imagem ou vídeo. Os algoritmos de visão computacional identificam os principais pontos de referência no rosto - por exemplo, os cantos das sobrancelhas, a ponta do nariz, os cantos da sua boca. Os algoritmos de aprendizado de máquina então analisam pixels nessas regiões para classificar as expressões faciais. As combinações dessas expressões faciais são então mapeadas para as emoções. A tecnologia Affectiva mede sete métricas de emoção: raiva, desprezo, nojo, medo, alegria, tristeza e surpresa. A base de dados deste software foi treinada por mais de 7,5 milhões de faces em 87 países.

Entre suas aplicações comerciais, esta tecnologia de reconhecimento de emoções é usada para ajudar as marcas a melhorar suas mensagens de publicidade e marketing. Outra aplicação importante tem sido na pesquisa política. No escopo deste trabalho a ferramenta CADAP acopla a API (Application Programming Interface) do Affectiva para reconhecimento das expressões faciais dos alunos durante as aulas e propõe uma nova aplicação para a ferramenta na área educacional. O segmento de educação ainda não foi explorado pelo Affectiva.

Este trabalho optou por utilizar uma ferramenta consolidada para reconhecimento de expressões faciais para aumentar a confiabilidades dos resultados, e para centrar seus esforços na investigação das correlações entre emoção e aprendizagem, que é o foco desta proposta.

\section{Resultados}

Até o momento já foram realizados vinte experimentos, que envolveram por volta de trezentos alunos e vinte docentes em algumas universidades da América Latina, onde os docentes preparam aulas e disponibilizam na ferramenta CADAP para que os alunos visualizem e suas emoções sejam monitoradas. A ferramenta captura as expressões faciais dos alunos durante a apresentação das videoaulas e ao final gera um arquivo no formato .csv com todas as capturas realizadas. As pontuações das emoções indicam quando os usuários mostram uma emoção ou expressão 
específica. Estas podem ser pensadas como detectores: à medida que a emoção ou expressão facial ocorre e se intensifica, a pontuação aumenta de 0 - sem expressão da emoção, para 100 - expressão da emoção totalmente presente. A Figura 7 é o recorte de um arquivo gerado pela ferramenta, após o término da visualização de uma aula por um aluno.

\begin{tabular}{|r|r|r|r|r|r|r|}
\hline \hline Alegria & Medo & Raiva & Desgosto & Tristeza & Desprezo & Surpresa \\
\hline 0 & 0 & 6 & 3 & 10 & 1 & 0 \\
\hline 0 & 0 & 12 & 5 & 16 & 1 & 0 \\
\hline 0 & 0 & 10 & 6 & 15 & 1 & 0 \\
\hline 0 & 0 & 11 & 7 & 20 & 1 & 0 \\
\hline 0 & 0 & 12 & 9 & 17 & 1 & 0 \\
\hline 0 & 0 & 15 & 10 & 14 & 1 & 0 \\
\hline 0 & 0 & 19 & 12 & 10 & 1 & 0 \\
\hline 0 & 0 & 20 & 12 & 9 & 1 & 0 \\
\hline 0 & 0 & 21 & 13 & 9 & 1 & 0 \\
\hline 0 & 0 & 22 & 13 & 9 & 1 & 0 \\
\hline 0 & 0 & 23 & 12 & 9 & 1 & 0 \\
\hline 0 & 0 & 23 & 13 & 10 & 1 & 0 \\
\hline 0 & 0 & 26 & 14 & 9 & 1 & 0 \\
\hline 0 & 0 & 31 & 15 & 8 & 1 & 0 \\
\hline
\end{tabular}

Figura 7. Recorte de um Arquivo de Captura gerado pela ferramenta

Assim, com estes dados coletados, é possível analisar e correlacionar as emoções dos alunos, com os conteúdos que foram apresentados a ele. Além de acompanhar a variação de emoções que ocorre durante as aulas, e saber exatamente em qual momento houve maior índice de emoções positivas ou negativas. O software somente armazena estas informações referentes a reações emocionais, não armazenando nenhuma filmagem dos alunos. Cabe ressaltar ainda que os alunos envolvidos nos experimentos já realizados concordaram em participar assinando um termo de consentimento disponibilizado na própria ferramenta de software e exibido na Figura 8.

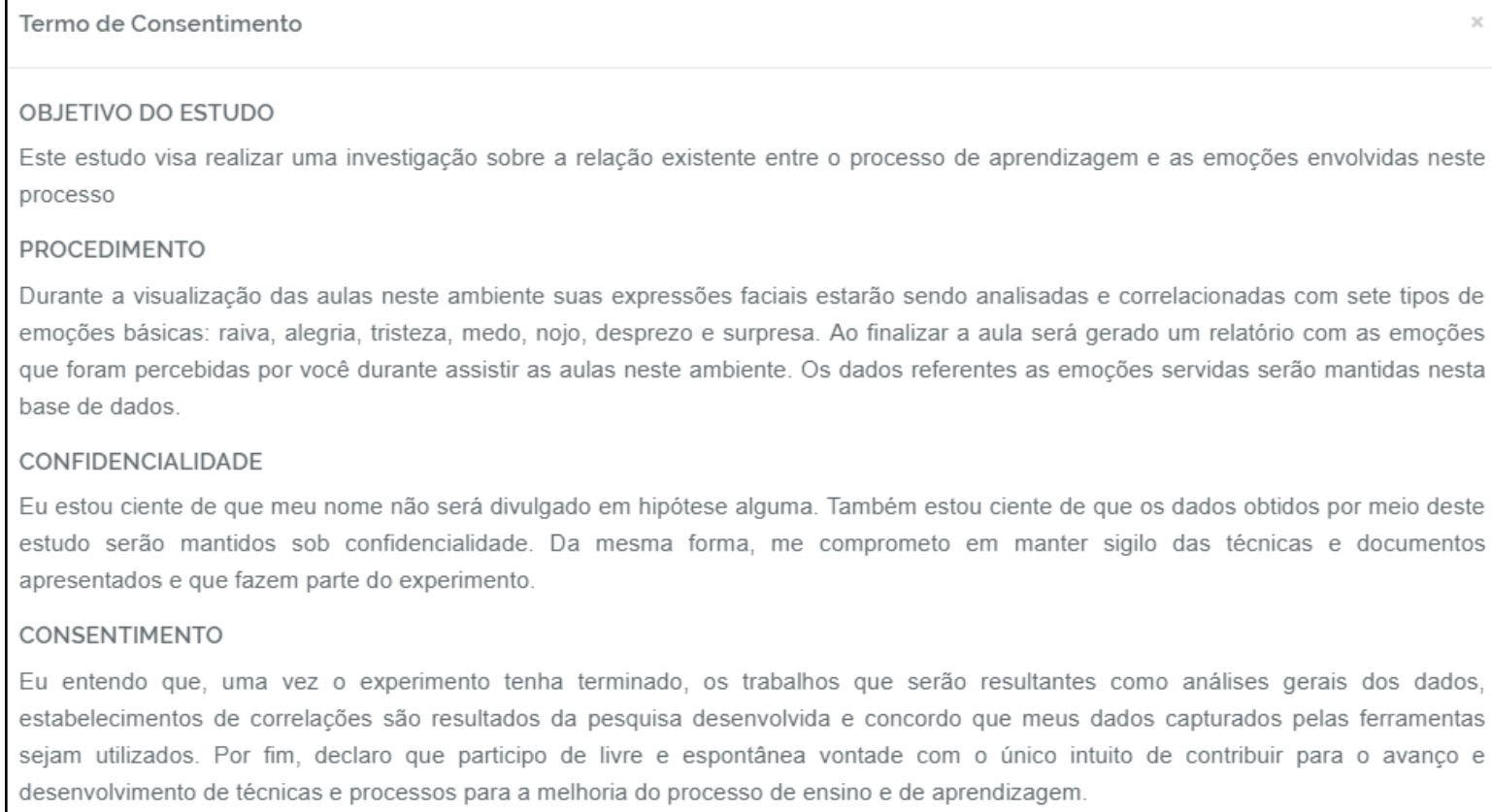

Figura 8. Termo de Consentimento

A Figura 9 apresenta um destes experimentos, onde um grupo de alunos assiste aulas no ambiente CADAP. Baseado nestes cenários, análises estão sendo feitas para que a ferramenta possa auxiliar nas medições apresentadas nas próximas seções. 


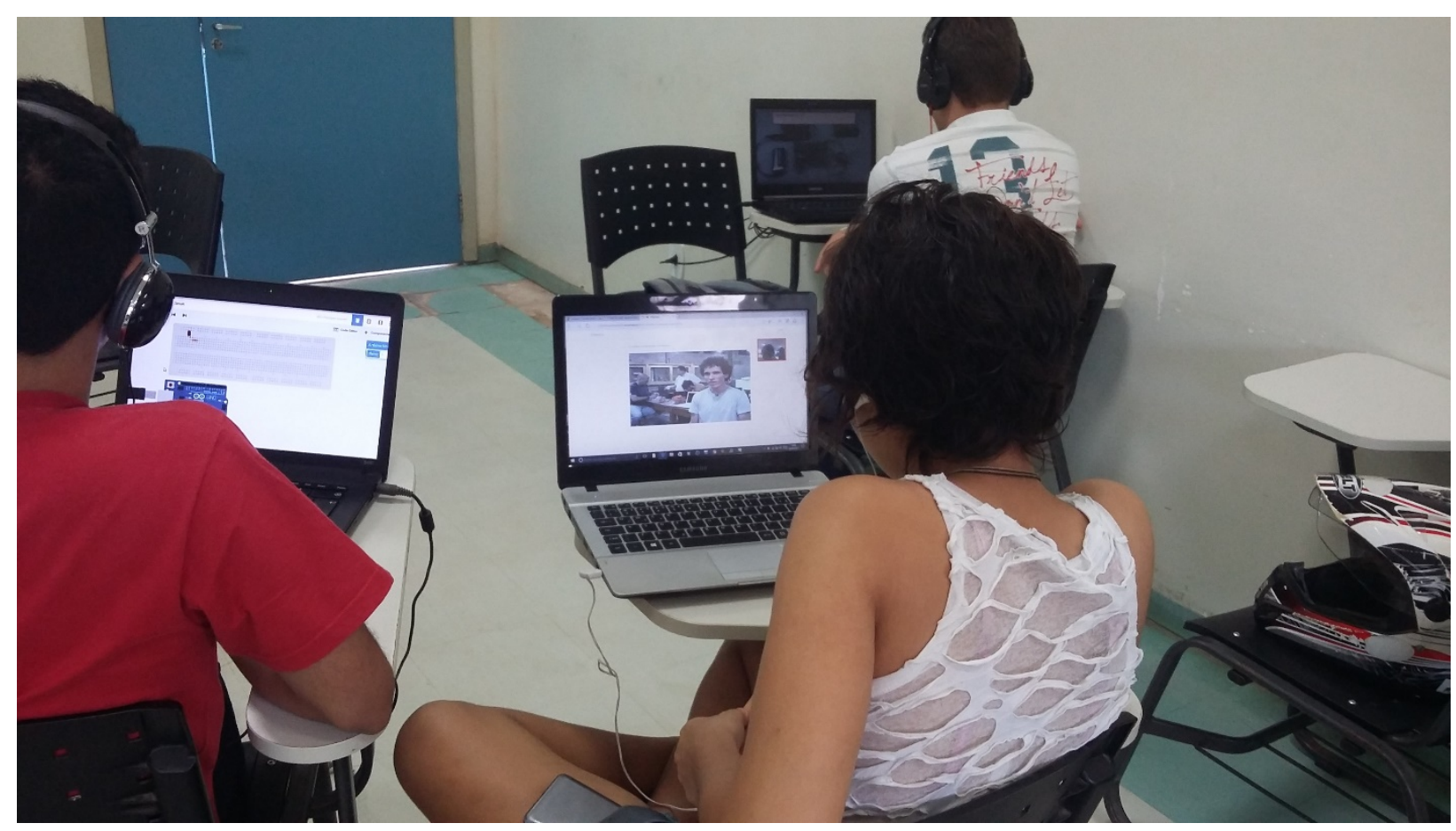

Figura 9. Aula de Eletrônica Digital

As próximas seções apresentam relações que puderam ser estabelecidas a partir da realização dos experimentos.

\subsection{Desempenho de Aluno por Aula}

Com os dados gerados pela ferramenta, já é possível analisar a média de emoções positivas e negativas dos alunos nas aulas e correlacionar estas informações com as avaliações realizadas sobre os assuntos tratados nas aulas. No gráfico da Figura 10, o eixo y apresenta a média de variação de emoções que é medida em uma escala entre 0 e 100, porém neste caso específico, a emoção que apresentou maior média atingiu o valor 15, e por este motivo optou-se por exibir o gráfico com uma escala entre 0 e 18. O eixo x apresenta cada uma das emoções de uma determinada aluna, acompanhada em cinco aulas com temas distintos - cubismo, dadaísmo, expressionismo, futurismo e surrealismo. Ao analisar os dados representados é possível verificar que esta aluna acompanhada teve desempenho mais baixo (percentual de acerto menor) na aula de expressionismo, onde houve predominância de emoções negativas como desprezo e nojo. Análises como essa podem ser feitas individualmente para todos os alunos que utilizarem a ferramenta, permitindo assim ao docente conhecer a reação emocional de cada um dos seus alunos e realizar intervenções individualizas. Análises estatísticas poderão ser feitas para encontrar correlações coletivas entre as reações emocionais do grupo e os conteúdos apresentados. 


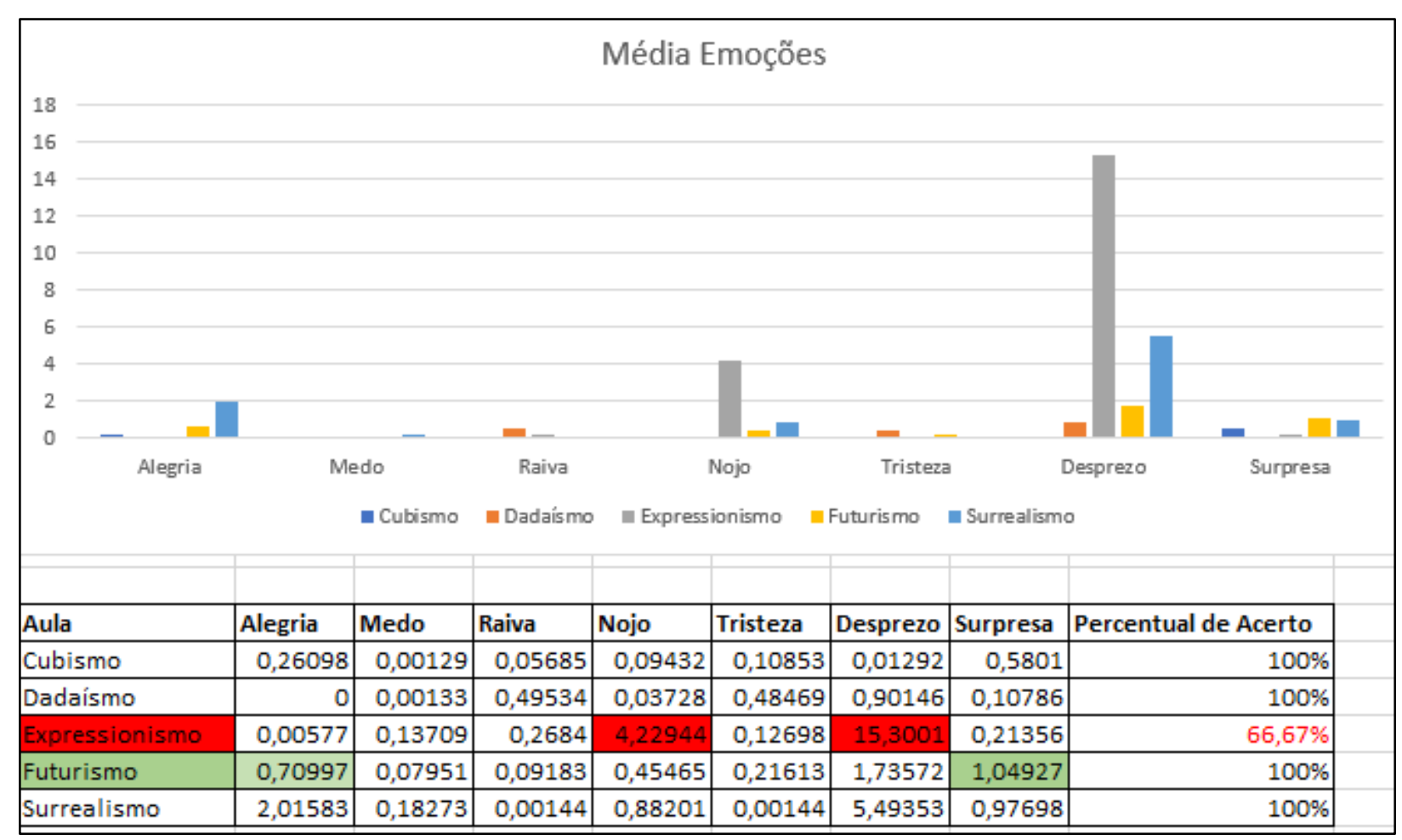

Figura 10. Média de Emoções e Desempenho de um Aluno

\subsection{Acompanhamento das Emoções da Turma}

A ferramenta permite ainda analisar a média das emoções dos alunos durante as aulas, possibilitando aos docentes saberem se os objetos de aprendizagem utilizados na disciplina despertam emoções positivas ou negativas nos alunos. A Figura 11 apresenta um exemplo, onde é possível analisar a média das emoções dos alunos em uma determinada aula e saber qual a emoção prevaleceu na turma. No gráfico apresentado, o eixo y apresenta as sete emoções analisadas pela ferramenta, e o eixo $\mathbf{x}$ a média das emoções da turma analisada. Nesta turma é possível verificar que as emoções positivas como alegria e surpresa predominaram entre os alunos.

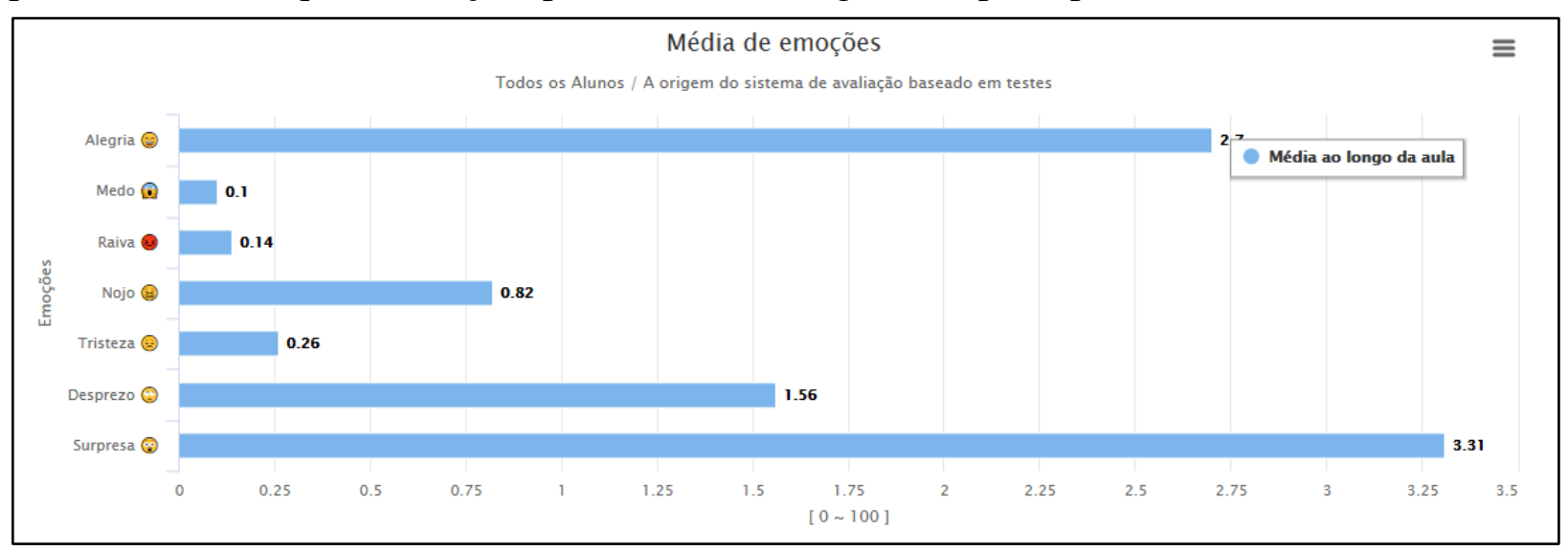

Figura 11. Média das Emoções dos Alunos de uma Turma

\subsection{Acompanhamento Individual dos Alunos}

Com base nos dados coletados pela ferramenta, é possível analisar a variação individual das emoções dos alunos, e com isso, o docente pode verificar como cada aluno reage ao conteúdo apresentado e analisar as possíveis causas de variação de emoções para cada aluno. 
A Figura 12 apresenta um gráfico gerado com os dados coletados pela ferramenta, que demonstra a variação de emoções individuais dos alunos de uma turma específica. No gráfico, o eixo y apresenta o nome dos alunos da turma e o eixo $\mathbf{x}$, a média de cada emoção. A variação entre os alunos é devida à intensidade de cada emoção captada pela ferramenta. Esta intensidade varia em uma escala de 0 a 100.

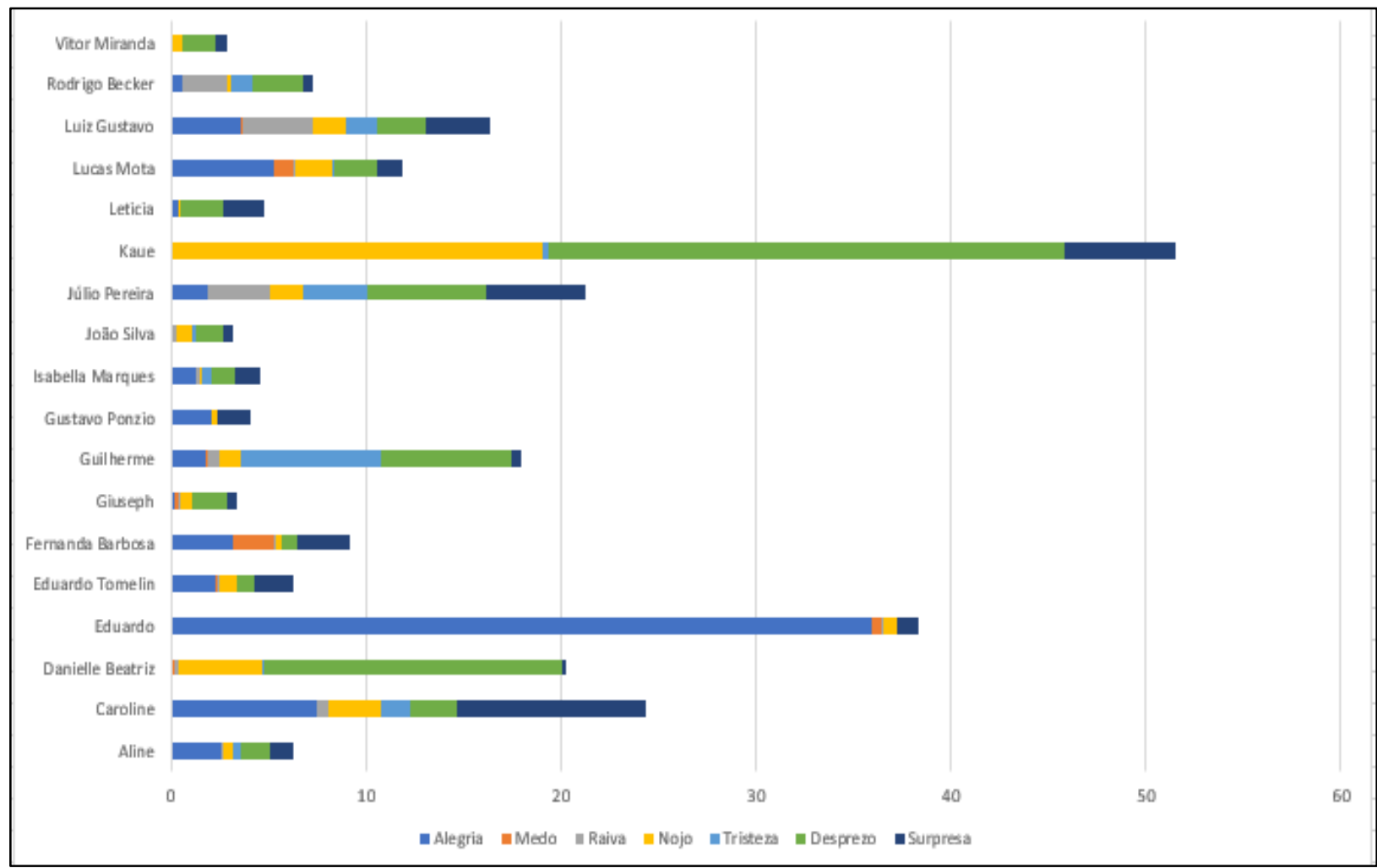

Figura 12. Variação das Emoções dos Alunos de uma Turma

Sabe-se que a variação das emoções dos alunos nem sempre estará relacionada ao ambiente de aprendizagem, pois o aluno pode já estar com estado emocional afetado por outras condições externas, porém a ferramenta pode auxiliar o professor a identificar estas situações. Um aluno que mesmo com a variação de conteúdos e objetos de aprendizagem sempre permanece com um determinado estado emocional, tristeza por exemplo, pode estar passando por alguma dificuldade, e a utilização de uma ferramenta como a proposta neste trabalho, pode ajudar o professor a perceber esta situação.

A ferramenta também pode auxiliar na identificação das variações significativas de estado emocional de um determinado aluno. A Figura 13 apresenta o relatório de acompanhamento individual gerado pela ferramenta que contém as médias de emoções de um aluno fictício para cada aula. Este relatório tem objetivo de detectar desvios significativos no padrão do aluno. 


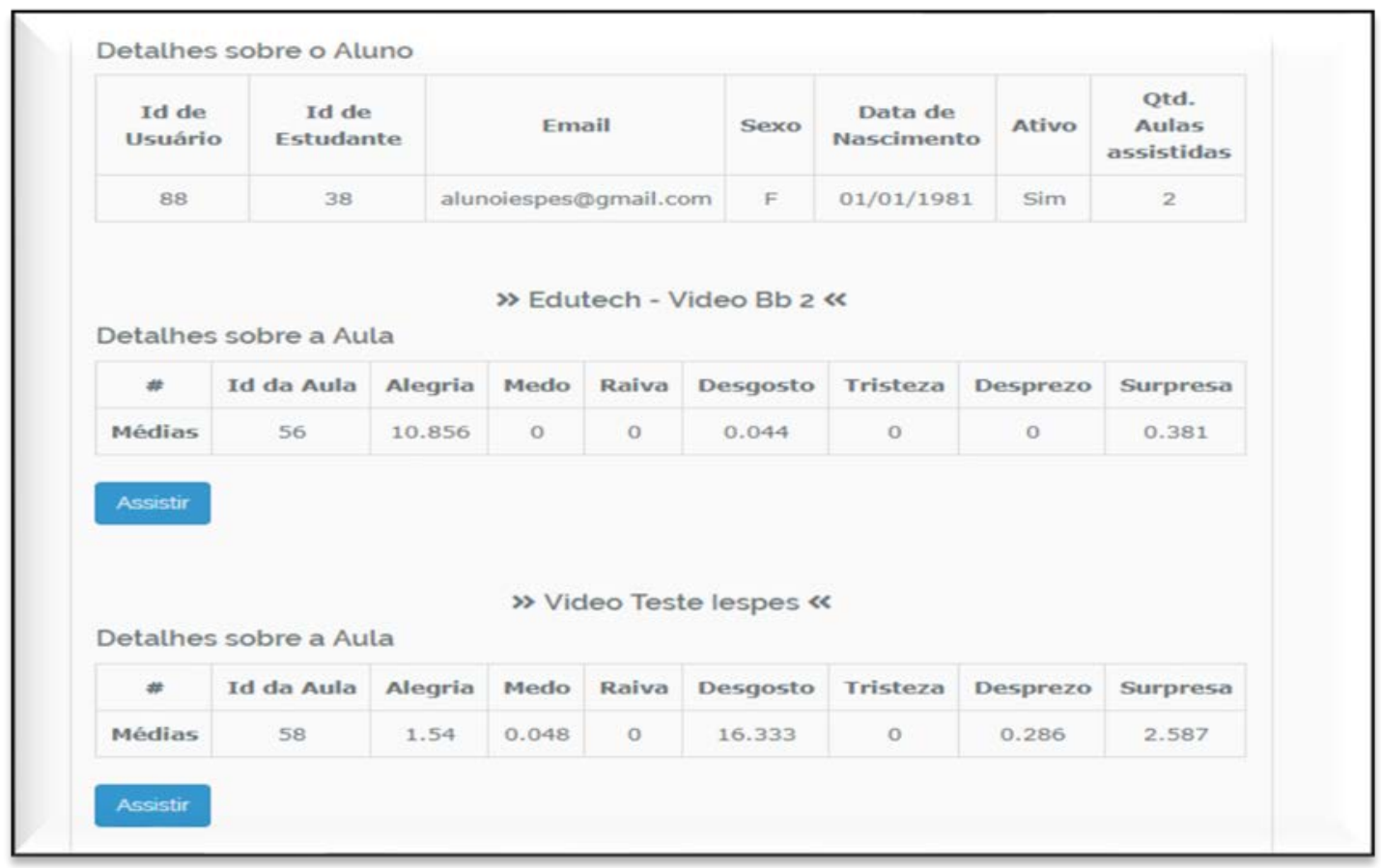

Figura 13. Acompanhamento Individual do Aluno

\section{Conclusão}

Este trabalho apresentou uma proposta de um modelo de ensino que utiliza as emoções dos alunos com objetivo de correlacioná-las com o processo de ensino e de aprendizagem. Neste modelo, as expressões faciais dos estudantes são automaticamente extraídas usando uma ferramenta de reconhecimento de expressões faciais - CADAP - ferramenta que foi desenvolvida pelos autores deste trabalho, com objetivo de ser suporte ao modelo proposto. Importante ressaltar que a ferramenta apenas mantém em sua base de dados informações referentes às emoções reconhecidas dos alunos, não sendo armazenada nenhuma imagem. Manter as imagens dos alunos, mesmo com o consentimento destes, poderia vir a ser uma questão controversa do trabalho por questões de privacidade, por este motivo, a abordagem escolhida armazena somente os dados numéricos referentes às variações emocionais dos alunos.

O modelo proposto está sendo utilizado em diferentes universidades e disciplinas com objetivo de analisar esta abordagem e os dados gerados pela ferramenta. Nos experimentos que estão sendo realizados, busca-se variar o conteúdo aplicado, as turmas e disciplinas com intuito de avaliar diferentes contextos de aplicação. Até o momento, estão sendo obtidos resultados promissores que indicam a viabilidade da utilização desta proposta em ambientes de aprendizagem presenciais e a distância. Os participantes dos experimentos avaliam que é possível utilizar este modelo para estabelecer correlações importantes entre emoções, conteúdos, metodologias, perfis e desempenho dos alunos. Estudos preliminares já indicam que há alterações nas reações emocionais dos alunos de acordo com as metodologias empregadas nas videoaulas utilizadas nos experimentos. Investigações mais detalhadas ainda serão realizadas com apoio de técnicas estatísticas para estabelecimento das correlações.

Em trabalhos futuros, serão desenvolvidos algoritmos com técnicas de aprendizado de máquina para atuar também na predição de informações. Atualmente, o modelo realiza diagnósticos, mas a intenção é que possa evoluir para atuar na indicação de conteúdos e 
metodologias baseado no histórico de reações emocionais dos alunos e ainda na prevenção de situações de retenção e evasão escolar.

\section{Referências}

Atkinson, R. L., Atkinson, R. C., Smith, E. E., Bem, D. J., \& Nolen-Hoeksema, S. (2002). Introdução à psicologia de Hilgard. Porto Alegre: Artmed.

Bercht, M., \& Viccari, R. (2000). Pedagogical Agents With Affective And Cognitive Dimensions. In $V$ Congreso Iberoamericnao De Informatica Educativa (pp. 4-6). [GS Search]

Coles, G. (1998). Literacy, Emotions, and the Brain. Retrieved from https://www.researchgate.net/publication/246704394_Literacy_emotions_and_the_brain. Access on 25/01/2019.

Conati, C., \& Zhou, X. (2002). Modelling Students' Emotions from Cognitive Appraisal in Educational Games. In International Conference on Intelligent Tutoring Systems (pp. 944954). Springer, Berlin, Heidelberg. doi: https://doi.org/10.1007/3-540-47987-2_94 [GS Search]

Damasio, A. (1996). O Erro de Descartes: emoção, razão e o cérebro humano. São Paulo: Companhia das Letras. [GS Search]

Darwin C. (1872). The expression of the emotions in man and animals. London: John Murray. [GS Search]

Davis, M., \& Lang, P. J. (2003). Emotion. In M. Gallagher \& R. J. Nelson (Eds.), Handbook of psychology-volume 3: Biological psychology. New Jersey: John Wiley\& Sons. [GS Search]

Dolog, P., \& Schaefer, M. (2005). A Framework for browsing manipulating and maintaining interoperable learner profiles. In International Conference on User Modeling (pp. 397-401). Springer Berlin, Heidelberg. doi: https://doi.org/10.1007/11527886_52 [GS Search]

D’Mello, S., Lehman, B., Sullins, J., Daigle, R., Combs, R., Vogt, K., ... \& Graesser, A. (2010). A time for emoting: When affect-sensitivity is and isn't effective at promoting deep learning. In International Conference on Intelligent Tutoring Systems (pp. 245-254). Springer, Berlin, Heidelberg. doi:10.1007/978-3-642-13388-6_29 [GS Search]

De Vicente, A., \& Pain, H. (2002). Informing The Detection Of The Students' Motivational State: An Empirical Study. In International Conference On Intelligent Tutoring Systems (p. 933943). Springer, Berlin, Heidelberg. doi: https://doi.org/10.1007/3-540-47987-2_93 [GS Search]

Ekman, P. (2003). Emotions revealed. New York: Times Book.

Elliott, C. (1997). Affective Reasoner Personality Models For Automated Tutoring Systems. In AI in Education Workshop on Pedagogical Agents (pp. 33-39). [GS Search]

Elliott, C., \& Brzezinski, J. (1998). Autonomous Agents As Synthetic Characters. AI Magazine 19(2), 13-13. doi: https://doi.org/10.1609/aimag.v19i2.1366 [GS Search]

Felder, R. M, \& Silverman, L. K. (1988). Learning and Teaching Styles in Engineering Education. Engineering Education, 78(7), 674-681. [GS Search]

Gazzaniga, M. S., \& Heatherton, T. F. (2005). Personalidade. Ciência psicológica: mente, cérebro e comportamento, 470-496. 
Georgeff, M., Pell, B., Pollack, M., Tambe, M., \& Wooldridge, M. (1998). The Belief-DesireIntention Model of Agency. In International workshop on agent theories, architectures, and languages (pp. 1-10). Springer, Berlin, Heidelberg. doi: https://doi.org/10.1007/3-54049057-4_1 [GS Search]

Goleman, D. (1995). Inteligência Emocional. Rio de Janeiro: Objetiva. [GS Search]

Goodwin, C. J. (2005). História da psicologia moderna. São Paulo: Cultrix. [GS Search]

Izard, C. E. (1984). Emotion-cognition relationships and human development. Emotions, Cognition, and Behavior, 17-37. [GS Search]

James, W. (1890). The principles of psychology. New York: Holt. [GS Search]

Ledoux, J. (1996). The emotional brain: The mysterious underpinnings of emotional life. New York: Simon \& Schuster. [GS Search].

Levenson, R. W. (1999). The intrapersonal functions of emotion. Cognition and Emotion, 13, 481-504. doi: https://doi.org/10.1080/026999399379159 [GS Search].

Liu, Y., \& Ginther, D. (1999). Cognitive Styles and Distance Education. Online Journal of Distance Learning Administration 2(3), 1-19. [GS Search]

Lundqvist, D., \& Öhman, A. (2005). Caught by the evil eye. In L. F. Barrett, P. M. Niedenthal, \& P. Winkielman (Eds.), Emotion and consciousness (pp. 97-122). New York: Guilford. [GS Search]

McDuff, D., El Kaliouby, R., Senechal, T., Amr, M., Cohn, J. F., Picard, R. (2013). AffectivaMIT Facial Expression Dataset (AM-FED): Naturalistic and Spontaneous Facial Expressions Collected "In-the-Wild". In IEEE Conference on Computer Vision and Pattern Recognition Workshops (pp. 881-888). doi: https://doi.org/10.1109/CVPRW.2013.130 [GS Search]

Mandler, G. (2003). Emotion. In D. K. Freedheim \& I. B. Weiner (Eds.), Handbook of psychology - volume 1: History of psychology (pp. 157-175). New Jersey: John Wiley \& Sons. [GS Search].

Markham, R., \& Wang, L. (1996). Recognition of emotion by Chinese and Australian children. Journal of Cross-Cultural Psychology, 27(5), 616-643. doi: https://doi.org/10.1177/0022022196275008 [GS Search]

Mora, F. (2013). NeuroEducación, solo se puede aprender aquello que se ama. Alianza Editorial. [GS Search]

Niedenthal, P. M., Krauth-Gruber, S., \& Ric, F. (2006). Psychology of emotion: Interpersonal, experiential, and cognitive approaches. New York: Psychology Press. [GS Search]

Picard, R. (1997). Affective Computing. Cambridge: MIT Press. [GS Search]

Piaget, J. (1989). A psicologia da criança. 17ed. Rio de Janeiro: Bertrand Brasil. [GS Search]

Plutchik, R. (2002). Emotions and life: Perspectives from psychology, biology and evolution. Washington, DC: American Psychological Association. [GS Search]

Schultz, D. P., \& Schultz, S. E. (2009). História da psicologia moderna. São Paulo: Cengage Learning. [GS Search]

Vygotsky, L. (1994). The problem of the environment. In: R. Van der Veer \& J. Valsiner (Orgs.), The Vygotsky reader (pp. 338-354). Oxford, UK: Basil Blackwell Ltd. [GS Search]

Vygotsky, L. (1962). Thought and Language. Cambridge, MA: MIT Press. [GS Search] 
Strongman, K. T. (2003). The Psychology of Emotion: From Everyday Life to Theory, West Sussex: Wiley and Sons. [GS Search]

Triantafillou, E., Pomportsis, A., \& Demetriadis, S. (2003). The Design and the formative evaluation of an adaptive educational system based on cognitive styles. Computers \& Education, 41(1), 87-103. doi: http://dx.doi.org/10.1016/S0360-1315(03)00031-9 [GS Search]

Wehrle T., \& Kaiser S. (2000). Emotion and Facial Expression. In International Workshop on Affective Interactions (pp. 49-63). Springer, Berlin, Heidelberg. doi: https://doi.org/10.1007/10720296_5 [GS Search] 